Supporting Information

\title{
In situ 3D-printing using a bio-ink of protein-photosensitizer conjugates for single cell manipulation
}

Akihiro Nishiguchi†, Gent Kapiti†, J. Robin Höhner†, Smriti Singh†, Martin Moeller†**

$\uparrow$ DWI - Leibniz-Institute for Interactive Materials, Forckenbeckstrasse 50, D-52056, Aachen, Germany

E-mail: moeller@dwi.rwth-aachen.de 
Table S1. Summary of the property of BSA-RB conjugates.

\begin{tabular}{cccccc}
\hline & RB & RB/BSA & Conversion & $\begin{array}{c}\text { Max. cyto- } \\
\text { compatible conc. }\end{array}$ & $\begin{array}{c}\text { Min. conc. for } \\
\text { gelation }\end{array}$ \\
\cline { 2 - 6 } & (equivalent) & & $(\%)$ & $(\mathrm{mM})$ & 0.5 \\
\hline RB & - & - & - & 0.25 & 0.17 \\
BSA-RB(5) & 0.5 & 4.9 & 33 & 0.34 & 0.23 \\
BSA-RB(3) & 0.25 & 2.8 & 38 & 0.46 & 0.34 \\
BSA-RB(2) & 0.1 & 2.0 & 67 & 0.9 & 0.5 \\
BSA-RB(1) & 0.03 & 0.65 & 72 & 1 & \\
\hline
\end{tabular}




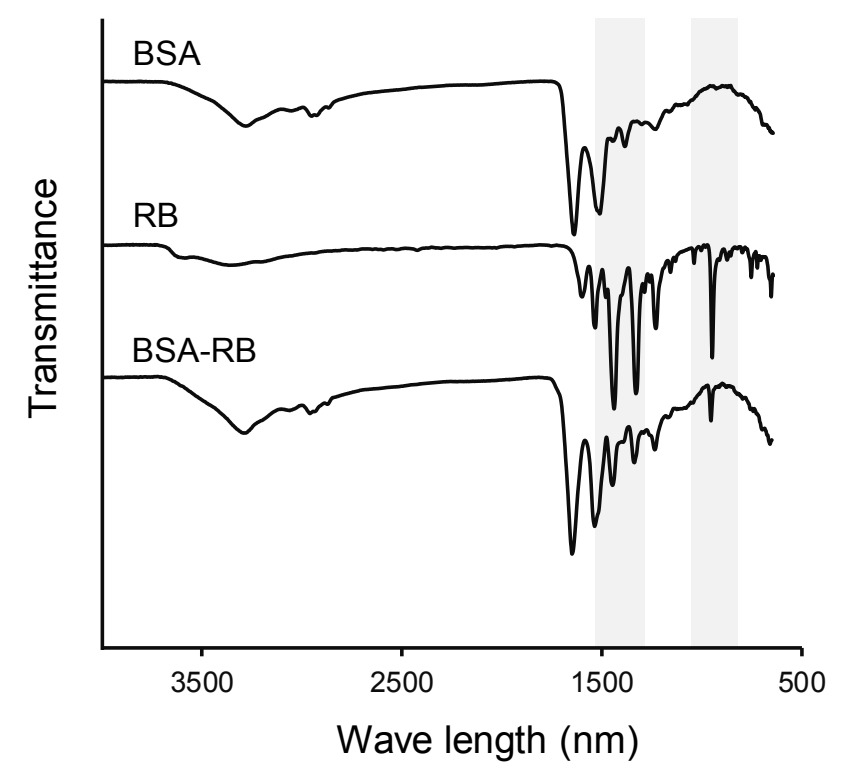

Figure S1. FT-IR spectrum of BSA, RB, and BSA-RB(2) conjugate. 
BSA
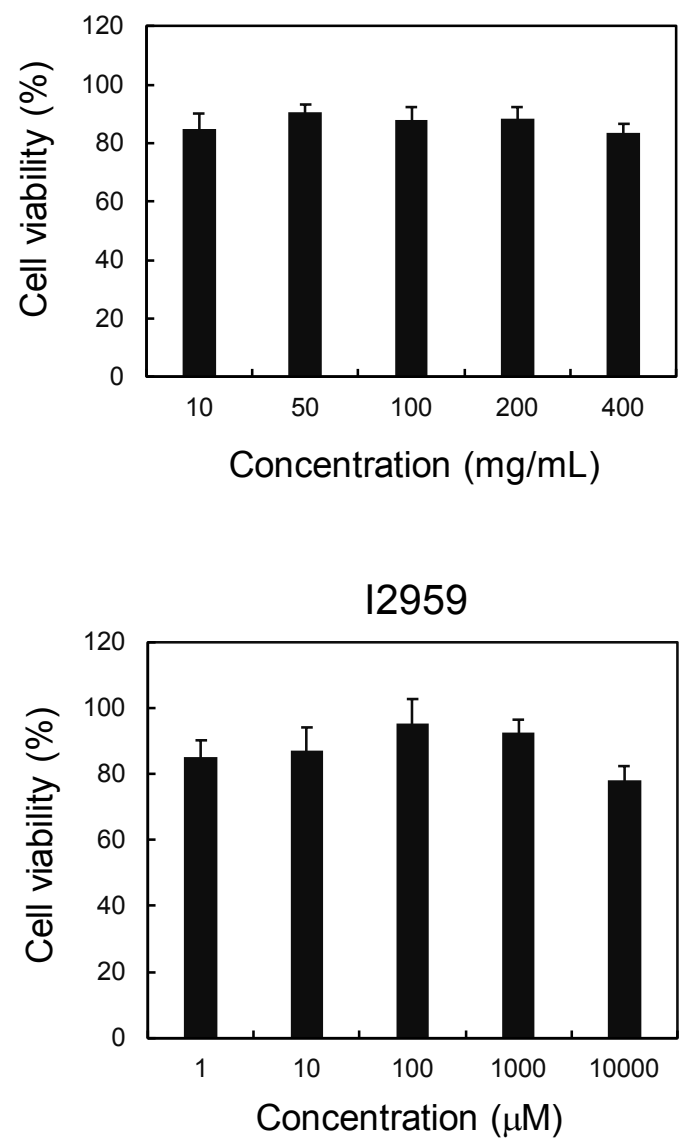

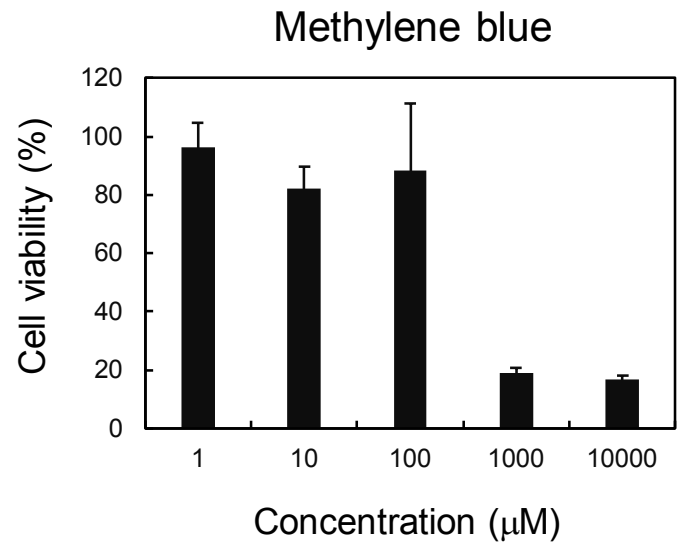

Figure S2. Cell viability measurement after 1 hour of exposure to various concentration of BSA, methylene blue, and I2959 by XTT assay. 
a
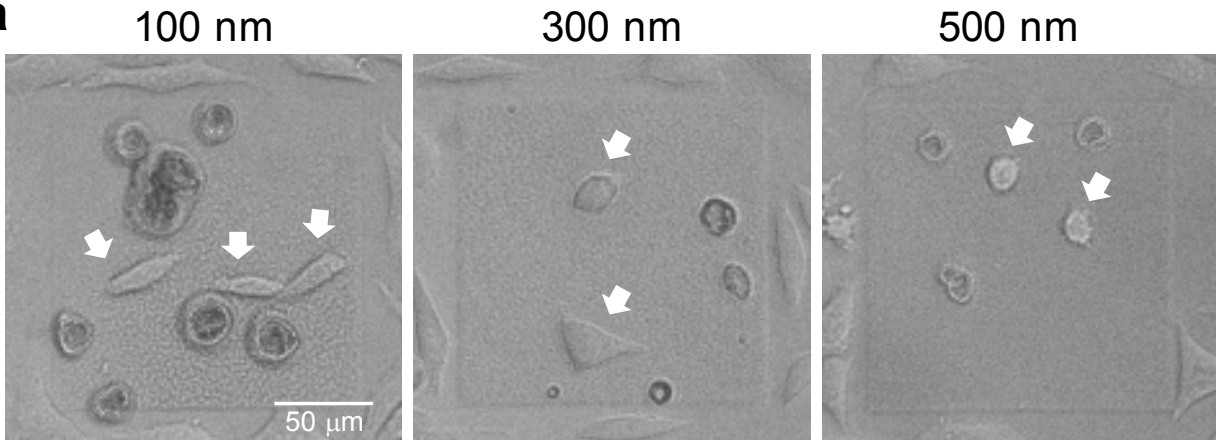

b

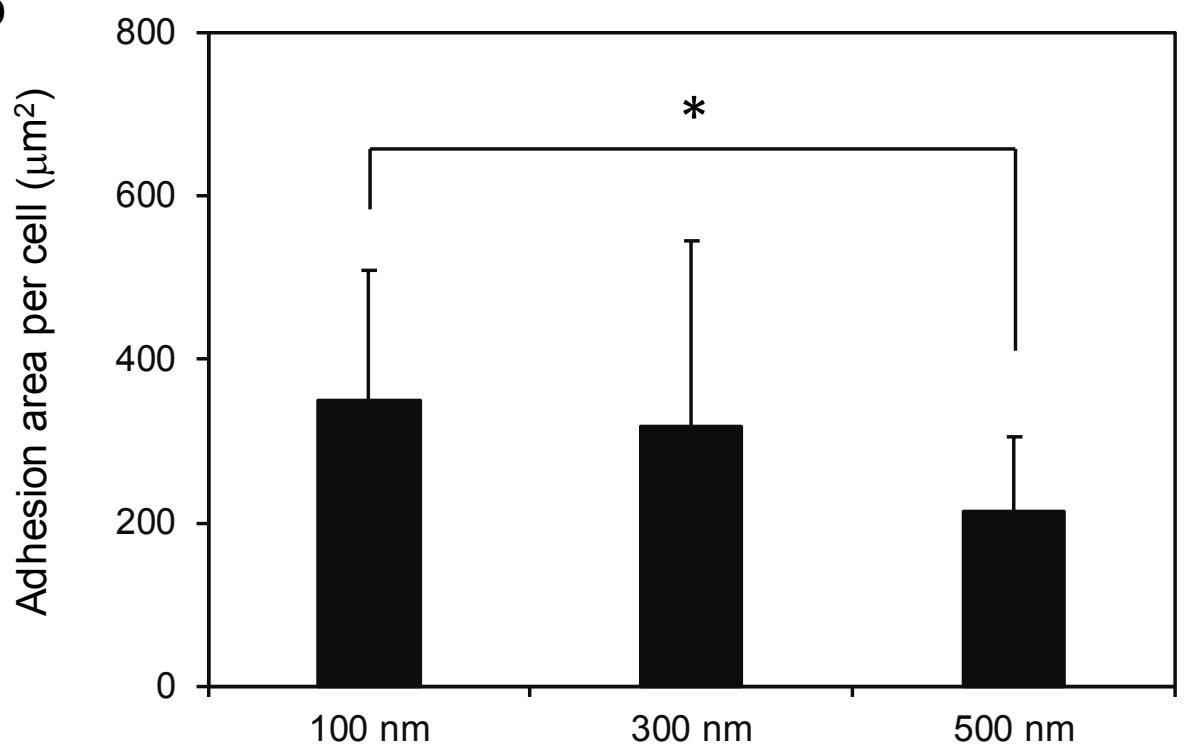

Figure S3. The relationship between adhesion area and stiffness of gels. (a) Phase contrast images of L929 cells adhered on gel films with different hatching/slicing distance in a range of 100 to $500 \mathrm{~nm}$ which were prepared before seeding (not in the presence of cells). 6,000 of L929 cells were seeded to $0.95 \mathrm{~cm}^{2}$ of area and cultured for 1 day. The white arrows denote cells. (b) Adhesion area per cell on each gels $(n>20)$. Cell adhesion area was measured by phase contrast images. ${ }^{*} P<0.05$, Tukey's multiple comparison test. 